\title{
Ultra Sharp Transition-Band Low-pass Filter with Miniaturized Size for GSM Applications
}

\author{
Gholamreza KARIMI ${ }^{1}$, Alireza GOLESTANIFAR ${ }^{2}$, Amirhossein GHADERI ${ }^{2}$, Navid SALIMPOUR ${ }^{2}$ \\ ${ }^{1}$ Electrical Department, Faculty of Engineering, Razi University, Kermanshah, Iran \\ ${ }^{2}$ Young Researchers and Elite Club, Kermanshah Branch, Islamic Azad University, Kermanshah, Iran
}

ghkarimi@razi.ac.ir, Golestany950@yahoo.com,Amir92h@yahoo.com, Navid_salimpour@yahoo.com

Submitted May 21, 2017 / Accepted January 16, 2018

\begin{abstract}
In this paper, a microstrip low-pass filter (LPF) using a bended transmission line is presented. The LPF has a simple topology, which is composed of a T-shaped stub as main resonator, one conventional rectangular resonator (as suppressing stub) and two T-shaped stubs. To approach a high operation and small dimensions, this structure is bent. The proposed LPF has a compact size $\left(0.090 \lambda_{g} \times\right.$ $\left.0.119 \lambda_{g}\right)$ and presents an ultra sharp transition-band $(\xi=880.95 \mathrm{~dB} / \mathrm{GHz})$ from 0.945 to $0.987 \mathrm{GHz}$ with -3 and $-40 d B$ suppression levels, respectively. This filter, with 3$d B$ cut-off frequency $\left(f_{c}\right)$ of $0.945 \mathrm{GHz}$, is useful for GSM applications. The performance of each section is investigated based on LC equivalent circuit. The designed filter is fabricated and measured. Also, the results exhibit an excellent figure of merit (FOM) of 239756.
\end{abstract}

\section{Keywords}

Low-pass filter, T-shaped resonator, transmission zero, LC equivalent circuit

\section{Introduction}

Microstrip low-pass filters (LPFs) with benefits like small size, wide stop-band and sharp cut-off are emerging requirements for implantation in wireless communication circuits such as; high frequency mixers and demodulators to reject interferer signals [1]. In [2], a microstrip LPF with high insertion-loss in the stop-band using $\mathrm{T}$-shaped and Z-shaped resonators was presented, to reduce the circuit size, transmission line was bent. In [3], a dual-layer LPF with wide rejection-band was depicted; however, enormous dimensions and slow cut-off are challenges of this work. In [4], a low-pass filter using T-shaped resonator was introduced, which gradual transition-band and large dimensions are disadvantages of this filter. In [5], a symmetrical LPF with high return-loss in the pass-band using T-shaped resonators was reported. To increase the stop-band width, four stepped-impedance suppressors were adopted, even though this filter does not have a sharp cut-off and small size. A miniaturized LPF with gradual cut-off frequency and narrow stop-band using funnel-shaped resonator was re- ported in [6], so that four triangle resonators were utilized to increase the sharpness. A simple LPF using steppedimpedance resonators was presented in [7]. This structure has a weak sharpness and large dimensions. In [8], an LPF with sharp cut-off and compact size using T-shaped resonator was introduced. The presented LPF in [9] was composed of several open-circuited stubs, which a fractal defected ground plane was embedded to decrease the circuit size. Also, this filter presents a slow transition-band and the limited stop-band. In [10], a microstrip LPF with acceptable stop-band width using $\mathrm{T}$-shaped resonators was reported, but the circuit dimensions are large. To develop the stop-band of the low-pass filter in [11], improved hairpin resonators were adopted; nonetheless the transition-band is slow. Multi-layer LPFs such as defected ground structure (DGS) [12-19], do not have a wide stop-band and sharp transition-band, moreover these filters suffer from complex structure.

In this work, a microstrip LPF with individual properties such as simple topology, ultra sharp transition-band, miniaturized size and very high FOM is proposed. To approach a sharp cut-off and wide stop-band, T-shaped and conventional rectangular resonators are employed. The simulation is performed by using the Keysight full-wave simulator Advanced Design System (ADS). Also, the proposed filter is manufactured on a Rogers_RO4003 substrate with $\varepsilon_{\mathrm{r}}=3.38, h=0.508 \mathrm{~mm}$ and loss-tangent of 0.002 .

\section{T-shaped Resonator Design}

In order to design a microstrip low-pass filter at GSM band, an LC resonator for a 3-pole elliptic low-pass filter is proposed, based on Fig. 1a. The element values of this resonator are obtained using (1) and (2), [1] as follows: $L_{1}=24.004 \mathrm{nH}, \quad L_{2}=6.866 \mathrm{nH}, \quad L_{3}=10.53 \mathrm{nH} \quad$ and $C_{1}=2.633 \mathrm{pF}$.

$$
\begin{gathered}
L_{i}=\frac{g_{\mathrm{L} i} Z_{0}}{2 \pi f_{\mathrm{c}}}, \\
C_{i}=\frac{g_{\mathrm{C} i}}{2 \pi f_{\mathrm{c}} Z_{0}}
\end{gathered}
$$




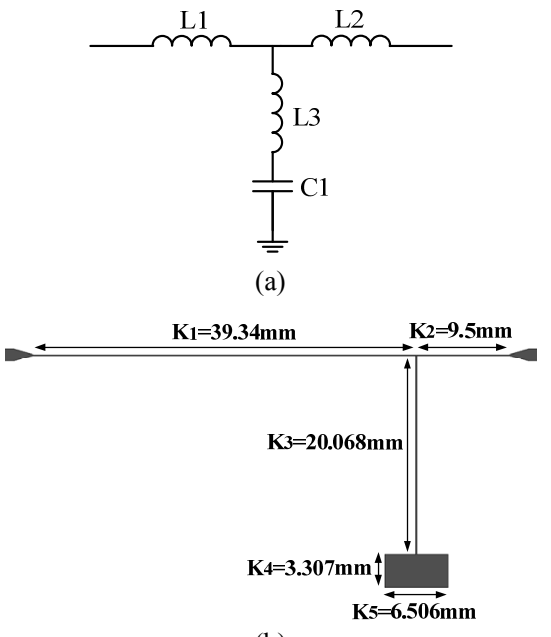

(b)

Fig. 1. T-shaped resonator: (a) LC, (b) layout.

where $Z_{0}$ is the line impedance $(50 \Omega) . g_{\mathrm{Li}}$ and $g_{\mathrm{Ci}}$ are applied to denote the inductive and capacitive elements, respectively. Also, $L_{1}$ and $L_{2}$ are inductances of the transmission line. $L_{3}$ describes the inductance of high-impedance stub and $C_{1}$ is equivalent capacitances of the open-circuited and low-impedance stubs. The layout of the $\mathrm{LC}$ resonator is presented in Fig. 1b. The physical lengths of the T-shaped resonator are computed using (3) and (4), [1]:

$$
\begin{gathered}
l_{\mathrm{L}}=\frac{\lambda_{\mathrm{gL}}}{2 \pi} \arcsin \left(\frac{\omega_{\mathrm{C}} L}{Z_{0 \mathrm{~L}}}\right), \\
l_{\mathrm{C}}=\frac{\lambda_{\mathrm{gC}}}{2 \pi} \arctan \left(\omega_{\mathrm{c}} C Z_{0 \mathrm{C}}\right)
\end{gathered}
$$

where $\lambda_{\mathrm{gL}}$ and $\lambda_{\mathrm{gC}}$ present the guided wave-length of high and low impedance lines, respectively. $\omega_{\mathrm{c}}$ is angular cut-off frequency, $Z_{0 \mathrm{~L}}$ and $Z_{0 \mathrm{C}}$ show the characteristic impedance of transmission line with high and low impedances, respectively. In addition, line calculator of Keysight ADS software can easily calculate the values of characteristic impedances.

The EM and LC simulations results of the T-shaped resonator are illustrated in Fig. 2a, where there is a good agreement between them. This resonator generates two transmission zeros $\left(\mathrm{T}_{\mathrm{Z} 1}\right.$ and $\left.\mathrm{T}_{\mathrm{Z} 2}\right)$ at 0.95 and $5 \mathrm{GHz}$ frequencies (seen in Fig. 2b) that the first transmission zero $\left(\mathrm{T}_{\mathrm{Z1}}\right)$ has more importance than another one, tuning the transition-band. Also, the second transmission zero $\left(\mathrm{T}_{\mathrm{Z} 2}\right)$ can provide a wide stopband.

The transfer function of the $\mathrm{T}$-shaped resonator is obtained from its LC circuit as follows:

$$
\frac{v_{\mathrm{o}}}{v_{\mathrm{i}}}=\frac{2 r\left(C_{1} L_{3} S^{2}+1\right)}{S^{3}\left(L_{1} C_{1} L_{3}+L_{1} C_{1} L_{2}+L_{2} C_{1} L_{3}\right)+a+b}
$$

where

$$
\begin{gathered}
a=S^{2}\left(2 r C_{1} L_{3}+r L_{1} C_{1}+r C_{1} L_{2}\right), \\
b=S\left(L_{1}+L_{2}+r^{2} C_{1}\right)+2 r,
\end{gathered}
$$

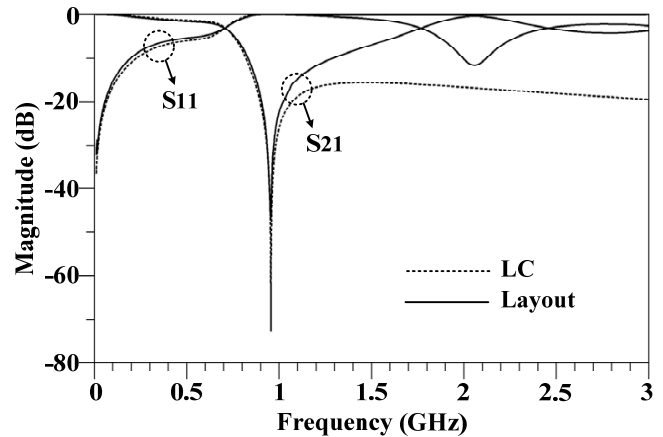

(a)

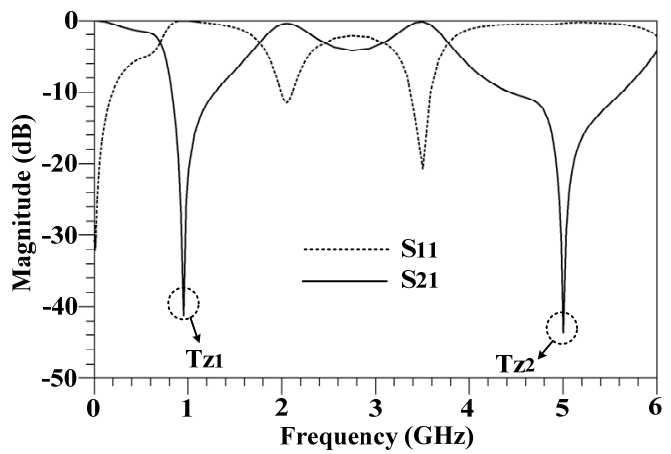

(b)

Fig. 2. T-shaped resonator: (a) EM and LC simulations, (b) EM simulation.

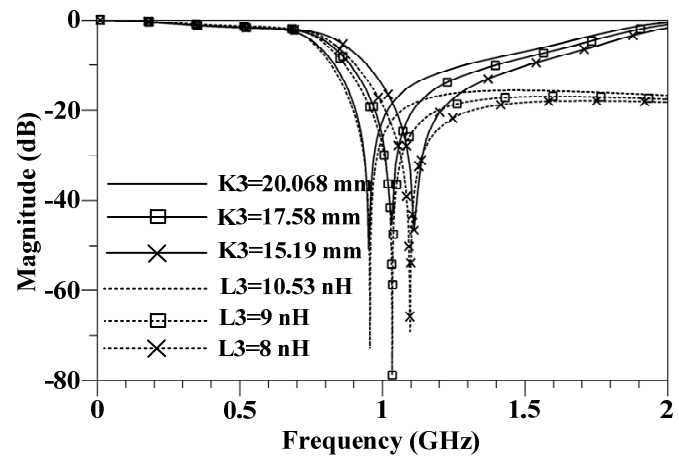

Fig. 3. EM-simulation of T-shaped resonator for different values of $L_{3}$ and $K_{3}$.

\begin{tabular}{|c|c|c|c|c|}
\hline \multicolumn{2}{|c|}{$\mathrm{K}_{3}(\mathrm{~mm})$} & 20.068 & 17.58 & 15.19 \\
\hline \multicolumn{2}{|c|}{$\mathrm{L}_{3}(\mathrm{nH})$} & 10.53 & 9 & 8 \\
\hline \multirow{2}{*}{$f_{\mathrm{z} 1}(\mathrm{GHz})$} & Simulated & 0.956 & 1.034 & 1.097 \\
\cline { 2 - 5 } & Calculated & 0.955 & 1.033 & 1.096 \\
\hline \multicolumn{2}{|c|}{ Transition-band $(\mathrm{GHz})$} & 0.189 & 0.221 & 0.248 \\
\hline
\end{tabular}

Tab. 1. Variations of $f_{z 1}$ for different values of $L_{3}$ and $K_{3}$.

$r$ is the matching impedance of input and output ports $(r=50 \Omega)$ and $S$ is equal to j2 $2 \pi f$ where $f$ is frequency. The equation of the $\mathrm{T}_{\mathrm{Z} 1}\left(f_{\mathrm{Z} 1}\right)$ is extracted from (5):

$$
f_{\mathrm{z} 1}=\frac{1}{2 \pi \sqrt{L_{3} C_{1}}} .
$$

According to (6), the $f_{\mathrm{z} 1}$ is a function of $L_{3}$ and $L_{3}$ is the inductance of $K_{3}$ in Fig. 1b. By decreasing the value of $L_{3}$, the length of $K_{3}$ is reduced, also. As a result, $\mathrm{T}_{\mathrm{Z1}}$ approaches to higher frequencies and transition-band is drowsed, as depicted in Fig. 3. So to have sharp transition- 
band, $\mathrm{T}_{\mathrm{Z} 1}$ is tuned at $0.95 \mathrm{GHz}$ frequency. The variations of $f_{\mathrm{z} 1}$ for different values of $L_{3}$ and $K_{3}$ are summarized in Tab. 1.

\section{LPF Design}

\subsection{Primitive LPF Design}

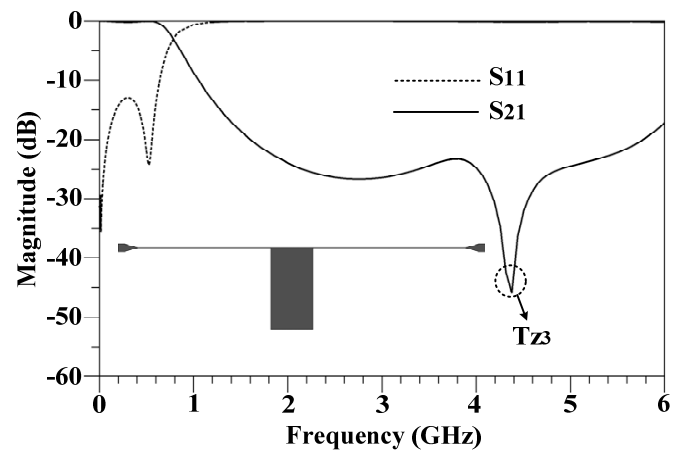

Fig. 4. EM simulation of conventional rectangular resonator.

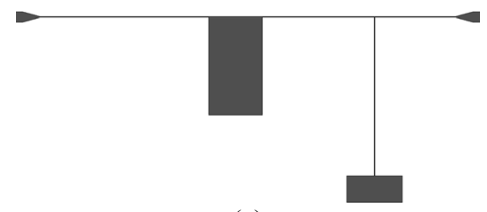

(a)

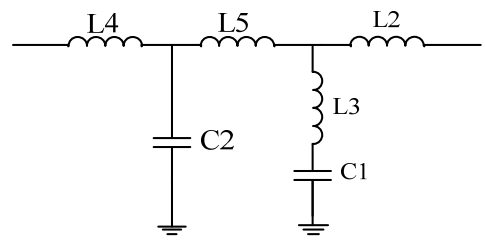

(b)

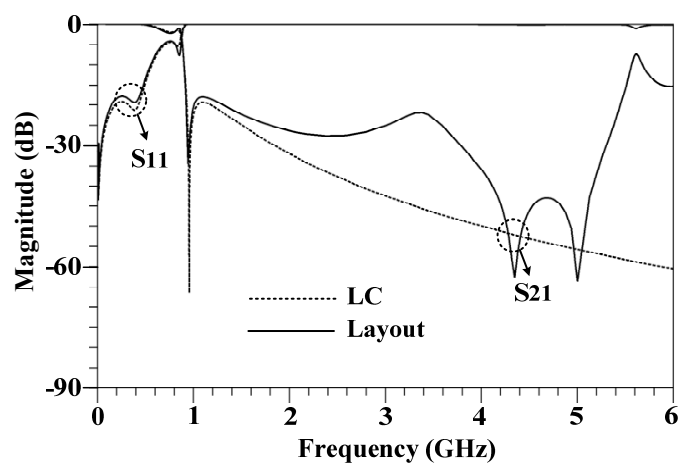

(c)

Fig. 5. Primitive LPF: (a) Layout, (b) LC equivalent circuit, (c) EM and LC simulations.
As seen in Fig. 2b, the stop-band is limited by transmission poles (TPs); to achieve a wide stop-band, TPs (from 1 to $5 \mathrm{GHz}$ ) should be suppressed. For this reason, a conventional rectangular resonator with wide stop-band (seen in Fig. 4) is added to the T-shaped resonator, based on Fig. 5a. The LC equivalent circuit of primitive LPF is depicted in Fig. 5b. $L_{4}$ and $L_{5}$ represent the inductances of transmission line. Capacitances of open-circuited and lowimpedance stubs are modeled by $C_{2}$. The LC equivalent circuit values using the methods discussed in [1] are computed as follows: $L_{4}=14 \mathrm{nH}, L_{5}=10.76 \mathrm{nH}$ and $C_{2}=$ $5.743 \mathrm{pF}$. The EM and LC simulations results are shown in Fig. $5 \mathrm{c}$ where a good agreement between them is seen. The stop-band of primitive LPF with $-18 \mathrm{~dB}$ attenuation level is extended up to $5.4 \mathrm{GHz}$.

\subsection{Improved LPF Design}

To have a LPF with high suppression level, high return-loss and low ripple in the pass-band, two T-shaped stubs (seen in Fig. 6) are added to primitive LPF, based on Fig. 7a. These stubs can provide a suitable suppression level by producing a transmission zero $\left(\mathrm{T}_{\mathrm{Z} 4}\right)$ at $1.175 \mathrm{GHz}$. The LC equivalent circuit of the improved LPF is demonstrated in Fig. $7 \mathrm{~b}$ where $L_{6}$ is the inductances of high-impedance stubs and $C_{3}$ is capacitances of open-circuited and low-impedance stubs. The $\mathrm{LC}$ equivalent circuit values are as follows: $L_{6}=8.4 \mathrm{nH}$ and $C_{3}=2.15 \mathrm{pF}$.

The transfer function of the improved LPF is presented in (7), transmission zeros can be extracted from it. The EM and LC simulation results and transfer function result are depicted in Fig. 7c. An acceptable agreement among them is seen, confirming the validation of the $\mathrm{LC}$ equivalent circuit and transfer function. This structure has negligible insertion-loss in the pass-band, high suppression level and sharp cut-off frequency.

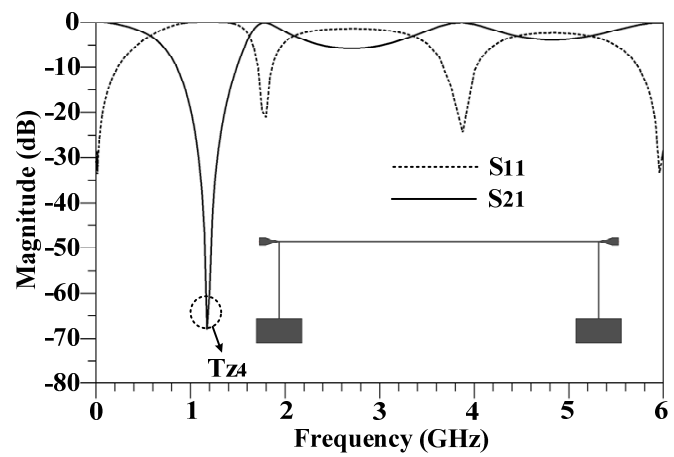

Fig. 6. EM simulation of T-shaped stubs.

$$
\begin{aligned}
\frac{v_{o}}{v_{i}}= & \frac{2 r\left(C_{3} L_{6} S^{2}+1\right)^{2}\left(C_{1} L_{3} S^{2}+1\right)}{\left(C_{3} L_{6} S^{2}+1\right)\left(C_{1} L_{3} S^{2}+1\right)\left(r^{2} C_{3} S+r^{2} C_{2} S\left(C_{3} L_{4} S^{2}+C_{3} L_{6} S^{2}\right)+\left(C_{3} L_{6} S^{2}+1\right)(b+r a)+\right.}, \\
& r L_{5} S^{2}\left(C_{3}+C_{2} C_{3} L_{4} S^{2}+C_{2}\left(C_{3} L_{6} S^{2}+1\right)\right)+r\left(C_{3} L_{6} S^{2}+1\right)\left(C_{2} L_{4} S^{2}\right)+r\left(C_{3} L_{4} S^{2}+C_{3} b S\right)+ \\
& \left.2 r\left(C_{3} L_{6} S^{2}+1\right)\right)+c
\end{aligned}
$$

where 


$$
\left.\begin{array}{c}
a=L_{2} S\left(\begin{array}{l}
\left(C_{1} L_{3} S^{2}+1\right)\left(C_{3} S+C_{2} C_{3} L_{4} S^{3}+C_{2} C_{3} L_{6} S^{3}+C_{2} S\right)+C_{1} S\left(C_{3} L_{6} S^{2}+1\right)+C_{1} C_{3} L_{4} S^{3}+ \\
\left(C_{3} L_{5} S^{2}\left(C_{3} S+C_{2} C_{3} L_{4} S^{3}+C_{2} S\left(C_{3} L_{6} S^{2}+1\right)\right)\right.
\end{array}\right), \\
\quad\left(C_{1} L_{3} S^{2}+1\right)
\end{array}\right),
$$

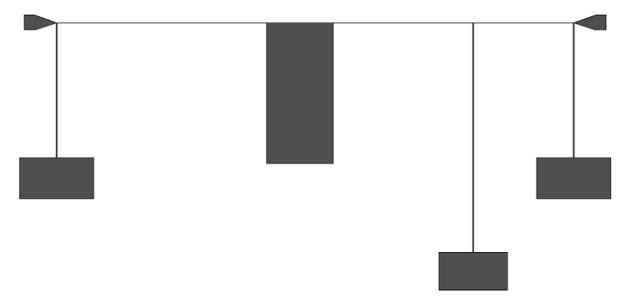

(a)

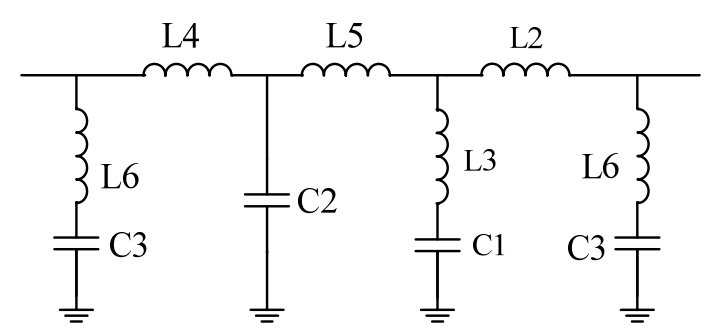

(b)

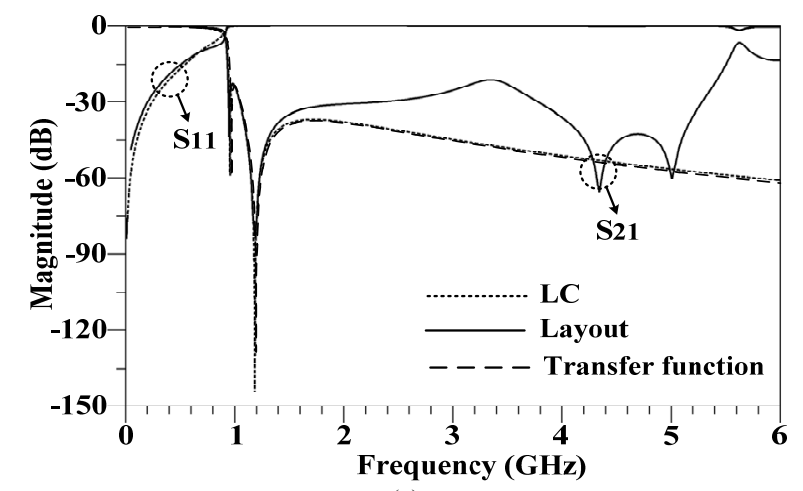

(c)

Fig. 7. Improved LPF: (a) Layout, (b) LC equivalent circuit, (c) EM and LC simulations and transfer function result.

\subsection{Proposed LPF}

The improved LPF has enormous dimensions (48.94 $\mathrm{mm} \times 23.45 \mathrm{~mm})$ and occupies a large area. So to reach a miniaturized size and high performance, this structure is bent, based on Fig. 8a. The final size of the proposed LPF is only $16.4 \mathrm{~mm} \times 21.65 \mathrm{~mm}$, which shows $69.06 \%$ size reduction in comparison with previous structure. Also, the proposed filter has an ultra sharp transition-band and a high suppression level in the stopband area. The physical size of the proposed LPF are: $A_{1}=15.6, A_{2}=6.3, A_{3}=6.2$, $A_{4}=9.4, \quad A_{5}=7, \quad A_{6}=6.5, \quad A_{7}=7, \quad A_{8}=9.3, \quad A_{9}=2.9$, $A_{10}=3.7, A_{\mathrm{m}}=1.2, H_{1}=2.6, H_{2}=5.4, H_{3}=12.4, H_{4}=3.3$, $H_{5}=0.1, H_{6}=1.4, H_{7}=3.6, H_{8}=0.1, H_{\mathrm{m}}=3, R_{1}=1$, $R_{2}=0.6$ (all in millimeter), $\theta_{1}=90^{\circ}$ and $\theta_{2}=90^{\circ}$.

\section{Simulated and Measured Results}

The photograph of the manufactured filter is displayed in Fig. 8b. Also, an Agilent N5230A network analyser is used to measure the manufactured filter. The simulated and measured results are observed in Fig. 8c. The proposed filter with 3 -dB cut-off frequency of $0.945 \mathrm{GHz}$ has an ultra sharp transition-band $(\xi=880.95 \mathrm{~dB} / \mathrm{GHz})$ from 0.945 to $0.987 \mathrm{GHz}(0.042 \mathrm{GHz})$ with suppression points of -3 and $-40 \mathrm{~dB}$, respectively. The insertion-loss in passband is $0.5 \mathrm{~dB}$. The stop-band of the structure with high suppression level of $-21 \mathrm{~dB}$ is expanded up to $5.401 \mathrm{GHz}$. The overall dimensions of the proposed structure are only $0.090 \lambda_{\mathrm{g}} \times 0.119 \lambda_{\mathrm{g}}$. Finally, this filter with very small size and high FOM (239756) is suitable for GSM applications. Based on some specifications mentioned in [2], the proposed LPF and the reported papers are compared in Tab. 2.

In this table, the sharpness of transition band is computed by $\xi=\left(\alpha_{\max }-\alpha_{\min }\right) /\left(f_{\mathrm{s}}-f_{\mathrm{c}}\right)$, where $\alpha_{\min }$ and $\alpha_{\max }$ are suppression points of -3 and $-40 \mathrm{~dB}$, respectively. Also, $f_{\mathrm{s}}$ is the frequency corresponding with $\alpha_{\max }$ and $f_{\mathrm{c}}$ is the frequency corresponding with $\alpha_{\min }$. SF means suppression factor and RSB is the relative stopband band-width for $-21 \mathrm{~dB}$ suppression level. The normalized circuit size is depicted by NCS. AF is architecture factor and FOM is defined as figure of merit that is given by $F O M=(\xi \times R S B \times S F) /(N C S \times A F)$. All of these parameters are defined in [2]. As seen from Tab. 2, the proposed LPF has the sharpest cut-off, the least size and the highest FOM in comparison with the published works. 


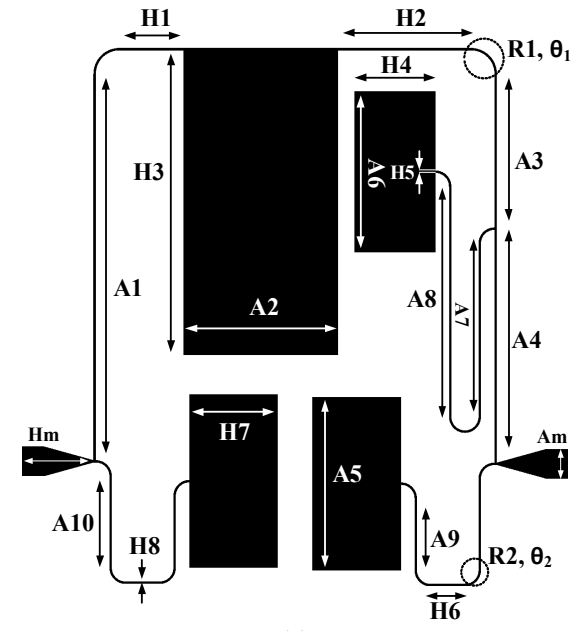

(a)

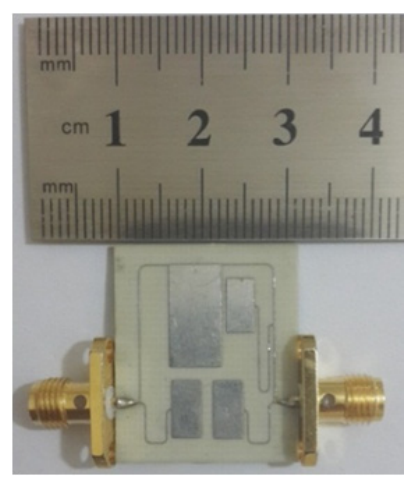

(b)

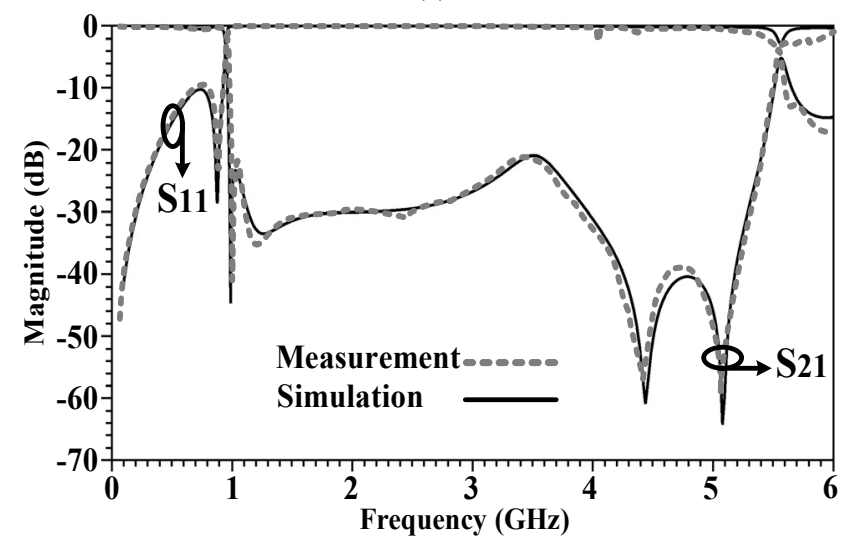

(c)

Fig. 8. The proposed filter: (a) Layout, (b) photograph of the fabricated filter, (c) simulated and measured results.

\section{Conclusion}

An ultra-sharp transition-band LPF with very small dimensions and very high FOM (239756) has been simulated, manufactured and tested. In this filter, to reach a sharp transition-band and wide stop-band, T-shaped and conventional rectangular resonators are employed. The designed LPF has a 3-dB cut-off frequency of $0.945 \mathrm{GHz}$, which it is appropriate for GSM communications. The other properties of the proposed LPF are: simple structure, high return-loss and wide rejection band. The final dimensions of the presented LPF are only $0.090 \lambda_{\mathrm{g}} \times 0.119 \lambda_{\mathrm{g}}$.

\begin{tabular}{|c|c|c|c|c|c|c|c|}
\hline Refs & $f_{\mathrm{c}}$ & $\xi$ & RSB & SF & NCS & AF & FOM \\
\hline$[3]$ & 1.89 & 137 & 1.69 & 2.5 & 0.017 & 1 & 32613 \\
\hline$[4]$ & 2.87 & 95.5 & 1.359 & 2 & 0.259 & 2 & 500.71 \\
\hline$[5]$ & 2.49 & 49 & 0.85 & 2 & 0.032 & 1 & 2603 \\
\hline$[6]$ & 2.28 & 94 & 1.26 & 2.3 & 0.041 & 1 & 6633.36 \\
\hline$[7]$ & 5.55 & 84 & 0.67 & 1.5 & 0.083 & 1 & 985 \\
\hline$[8]$ & 1 & 200 & 1.36 & 2 & 0.18 & 1 & 3022 \\
\hline$[10]$ & 1.8 & 250 & - & 2 & 0.251 & 2 & - \\
\hline$[11]$ & 1.02 & 131.2 & 1.66 & 2 & 0.009 & 1 & 46274.2 \\
\hline$[13]$ & 2.73 & 205.5 & 1.308 & 4 & 0.056 & 1 & 19165 \\
\hline$[14]$ & 2.9 & 48.85 & 1.33 & 2 & 0.016 & 1 & 7879 \\
\hline $\begin{array}{c}{[18]} \\
\text { (Filter1) }\end{array}$ & 1 & - & 1.14 & 3.1 & 0.001 & 2 & - \\
\hline $\begin{array}{c}{[18]} \\
\text { (Filter2) }\end{array}$ & 1 & 75 & - & 2.5 & 0.004 & 2 & - \\
\hline$[19]$ & 1.18 & 36.3 & 1.32 & 1.5 & 0.006 & 1 & 11543 \\
\hline $\begin{array}{c}\text { This } \\
\text { work }\end{array}$ & $\mathbf{0 . 9 4}$ & $\mathbf{8 8 0 . 9 5}$ & $\mathbf{1 . 3 8 8}$ & $\mathbf{2 . 1}$ & $\mathbf{0 . 0 1 0}$ & $\mathbf{1}$ & $\mathbf{2 3 9 7 5 6}$ \\
\hline
\end{tabular}

Tab. 2. Comparison among reported works and the proposed filter.

\section{References}

[1] HONG, J.-S., LANCASTER, M. J. Microstrip Filters for RF/Microwave Applications. John Wiley \& Sons, Inc., 2001. DOI: $10.1002 / 0471221619$

[2] KARIMI, G., SIAHKAMARI, H., HAMEDANI, F. K., et al. Design of modified Z-shaped and T-shaped microstrip filter based on transfer function analysis. Wireless Personal Communications, 2015, vol. 82 , no. 4, p. 2005-2016. DOI: $10.1007 / \mathrm{s} 11277-015-$ 2328-z

[3] ZHANG, Y., JIN, L., LI, L. Design of LPF using Hi-Lo interdigital DGS slot. IEICE Electronics Express, 2016, vol. 13, no. 9, p. 1-6. DOI: 10.1587/elex.13.20160175

[4] YANG, R. Y., LIN, Y. L., HUNG, C. Y., et al. Design of a compact and sharp-rejection low-pass filter with a wide stopband. Journal of Electromagnetic Waves and Applications, 2012, vol. 26, no. 17-18, p. 2284-2290. DOI: 10.1080/09205071.2012.733495

[5] RAPHIKA, P. M., ABDULlA, P., JASMINE, P. M. Planar elliptic function lowpass filter with sharp roll-off and wide stopband. Microwave and Optical Technology Letters, 2016 vol. 58 , no. 1 , p. 133-136. DOI: $10.1002 /$ mop. 29520

[6] RAPHIKA, P. M., ABDUlla, P., JASMine, P. M. Compact lowpass filter with a sharp roll-off using patch resonators. Microwave and Optical Technology Letters, 2014, vol. 56, no. 11, p. 2534-2536. DOI: $10.1002 /$ mop.28644

[7] ASADBEIGI, H., VIRDEE, B. S. Compact notch filter design using stepped impedance resonators for sharp roll-off and large wideband rejection. International Journal of $R F$ and Microwave Computer-Aided Engineering, 2015, vol. 25, no. 6, p. 490-494. DOI: $10.1002 /$ mmce. 20883

[8] AFZALI, B., KARKHANEHCHI, M. M., KARIMI, G. Design of compact microstrip lowpass filter with ultra-wide stopband using modified T-shaped resonator. International Journal of Microwave and Wireless Technologies, 2015, vol. 7, no. 06, p. 699-703. DOI: 10.1017/S175907871400124X

[9] KUFA, M., RAIDA, Z. Lowpass filter with reduced fractal defected ground structure. Electronics Letters, 2013, vol. 49, no. 3 , p. 199-201. DOI: 10.1049/el.2012.3473

[10] MOUSAVI, S. M. H., MAKKI, S. V. A. D., SIAHKAMARI, H. Design of microstrip lowpass filter using bend configuration with 
excellent sharpness in transition band. Frequenz, 2016, vol. 70, no. 5-6, p. 237-243. DOI: 10.1515/freq-2015-0096

[11] HAYATI, M., VAZIRI, H. S. Compact microstrip low-pass filter with wide stop-band and sharp roll-off. Frequenz, 2013, vol. 67, no. 9-10, p. 263-269. DOI: 10.1515/freq-2012-0151

[12] KUMAR, A., VERMA, A. K. Design of Bessel low-pass filter using DGS for RF/microwave applications. International Journal of Electronics, 2016, vol. 103, no. 9, p. 1460-1474. DOI: $10.1080 / 00207217.2015 .1126860$

[13] SUHAS, D., LAKSHMI, C. R., SRINIVASA RAO, Z., et al. A systematic implementation of elliptic low-pass filters using defected ground structures. Journal of Electromagnetic Waves and Applications, 2015, vol. 29, no. 15, p. 2014-2026. DOI: 10.1080/09205071.2015.1073635

[14] KUMAR, D., DE, A. Design of compact low pass microstrip filter for wireless communication system. Frequenz, 2011, vol. 65, no. 5-6, p. 127-130. DOI: 10.1515/freq.2011.022

[15] ZHANG, P., LI, M. A novel sharp roll-off microstrip lowpass filter with improved stopband and compact size using dual-plane structure. Microwave and Optical Technology Letters, 2016, vol. 58 , no. 5, p. 1085-1088. DOI: 10.1002/mop.29753

[16] XIAO, M., SUN, G., LI, X. A lowpass filter with compact size and sharp roll-off. IEEE Microwave and Wireless Components Letters, 2015, vol. 25 , no. 12 , p. 790-792. DOI: 10.1109/LMWC.2015.2496801

[17] LIU, S., XU, J., XU, Z. Sharp roll-off lowpass filter using interdigital DGS slot. Electronics Letters, 2015, vol. 51, no. 17, p. 1343-1345. DOI. 10.1049/el.2015.0721

[18] DURAN-SINDREU, M., BONACHE, J., MARTIN, F. Compact elliptic-function coplanar waveguide low-pass filters using backside metallic patterns. IEEE Microwave and Wireless Components Letters, 2010, vol. 20, no. 11, p. 601-603. DOI: 10.1109/LMWC.2010.2066961

[19] WANG, J., XU, L. J., ZHAO, S., GUO, Y. X., WU, W. Compact quasi-elliptic microstrip lowpass filter with wide stopband. Electronics Letters, 2010, vol. 46, no. 20, p. 1384-1385. DOI: $10.1049 / \mathrm{el} .2010 .1569$

\section{About the Authors ...}

Gholamreza KARIMI received his B.Sc., M.Sc., and $\mathrm{Ph} . \mathrm{D}$. degrees in Electrical Engineering from the Iran University of Science and Technology, Tehran, Iran, in 1999, 2001, and 2006, respectively. Since 2007, he has been with the Electrical Department, Razi University, Kermanshah, Iran, where he is now an Associate Professor. His main research interests are low power analog and digital IC design; RF IC design; and modeling and simulation of RF/mixed signal IC. He is also interested in microwave devices and artificial intelligence systems.

Alireza GOLESTANIFAR was born in Kermanshah, Iran in 1993. He received his B.Sc. and M.Sc. degrees in Electronics Engineering from the Islamic Azad University, Kermanshah, Iran in 2015 and 2017, respectively. He is member of the Applied Computational Electromagnetics Society (ACES). His current research includes microwave passive circuits and RF integrated circuit design.

Amirhossein GHADERI was born in Kermanshah, Iran in 1992. He received his B.Sc. and M.Sc. degrees in Electronics Engineering from the Islamic Azad University, Kermanshah, Iran in 2015 and 2017, respectively (Honor). He has been selected as the best student in the Electronics Engineering Department and awarded by the university president in 2014. He is now member of the Young Researchers and Elite Club. His current research includes microwave passive circuits and RF integrated circuit design.

Navid SALIMPOUR was born in Kermanshah, Iran in 1992. He received his B.Sc. degree in Electronics Engineering in 2015 from the Islamic Azad University, Kermanshah, Iran. He is member of the Islamic Azad University Kermanshah Branch, Young Researches Club. His current research includes RF/microwave circuit and digital integrated circuit design. 